\title{
EVOLUÇÃO DO PACIENTE: ANOTAÇŌES DE ENFERMAGEM NO KARDEX E PASSAGEM DE PLANTÃO COM EQUIPE MULTIPROFISSIONAL
}

\author{
* Vera Lucia Regina Maria \\ * Kazume Horigoshi Iwakura \\ * Theresinha Avila Lim \\ ** Sonia Lima Medeiros
}

RBEn/02

MARIA, V.L.R. e colaboradores - Evoluçāo do paciente: anotaçōes de enfermagem no kardex e passagem de plantāo com equipe multiprofissional. Rev. Bras. Enf.; DF, $30: 237-243,1977$.

\section{1 - CONSIDERAÇOESS GERAIS:}

O Instituto de Cardiologia do Estado teve seu início na Av. Paulista, há 20 anos passados. Graças aos esforços médicos daquele tempo ele cresceu e em 1958 foi transferido para o Ibirapuera funcionando somente o Ambulatório com Raio $X$, Laboratório e Eletrocardiograma. A internação dos pacientes era feita em convênio com a Beneficiência Portuguêsa. $O$ número de matriculados aumentou e consequentemente apareceu a necessidade de construir um prédio para internação. Em 29 de dezembro de 1971, foi inaugurado 0 prédio destinado ao hospital, iniciando nesta ocasião as admissōes de pacientes para tratamento cirúrgico-clínico, exames de cateterismo cardiaco e hemodiálise.

O Instituto de Cardiologia hoje chamado Instituto "Dante Pazzanese" de Cardiologia, homenagem póstuma ao $\mathrm{Di}$ retor Dr. Dante Pazzanese, conta com 157.000 matriculados, o prédio é uma construção em monobloco com capacidade para 100 leitos, estes pela demanda atual tornaram-se insuficientes havendo projetos para construção de novos prédios.

O Serviço de Enfermagem inicialmente planejado e organizado pelas enfermeiras Berenice M. Martinez e Maria Perales tem continuado com Gilka Sampaio Garcia, Diretora de Enfermagem em exercicio, que vem mantendo os prin-

* Enfermeiras.

** Assistente Social. 
MARIA, V.L.R. e colaboradores - Evolução do paciente: anotaçōes de enfermagem no kardex e passagem de plantão com equipe multiprofissional. Rev. Bras. Enf.; DF, 30 : 237-243, 1977.

cípios básicos planejando e adotando padrōes novos peculiares a equipe de trabalho e as modificações da organização hospitalar.

Como um dos princípios básicos planejado temos mantido a filosofia de trabalho, em equipe, e o sistema de registro nas fichas Kardex. Várias modificações foram feitas no serviço de enfermagem, mas o encontro da equipe de profissionais, nas passagens de plantão não foi interrompida 1 (um) só día nos 5 anos de existência do Hospital. $O$ uso e as anotaçōes da ficha Kardex foram feitas nos três períodos das 24 horas durante os 5 anos.

As primeiras anotações na ficha Kardex eram feitas à lápis e depois apagadas. Por sugestão da Dra. Aracy L. Viazolli dos Santos, Prof. a Assistente do Departamento de Clinica Médica da U.S.P., passamos a registrá-las à tinta com o objetivo de guardar como documentação e pesquisa. Segundo a mesma "as anotaçōes são valiosas e não devem ser apagadas". Usando nossos arquivos conseguimos fazer este trabalho.

Cooperaram conosco assistentes sociais, nutricionistas, terapeuta ocupacional e médicos residentes.

\section{2 - FINALIDADE:}

A finalidade deste trabalho é transmitir nossa experiência com o uso das anotações em Kardex, com a equipe multiprofisisonal nas passagens de plantão. problemas vividos para manter funcionando e principalmente promover discussões sobre 0 assunto.

\section{3 - OBJETIVOS:}

Queremos demonstrar que:

- O Kardex é meio prático de anotação;
- Funciona como meio de comunicação nas reuniōes da equipe multiprofissional;

- Pode ser usado como documentaçāo do trabalho realizado - auditoria;

- Pode ser usado com meio de pesquisa.

\section{4 - KARDEX:}

\section{1 - O que é o Kardex?}

- Definição - São impressos de papel cartão (fichas) - com 5 × 8 polegadas; usadas em 2 (dois) modelos. A 1.8 para entrevista identificando o paciente e a $2^{a}$ de problemas e recomendaçōes. As fichas são arquivadas em uma prancha de projeção (papelão grosso). Temos uma prancha para cada pôsto nas unidades, facilitando o manuseio e a consulta.

\section{2 - Composição do Kardex:}

4.2.1 - Ficha de entrevista, com os dados de identificação, condições gerais, condiçōes específicas, condiçōes psicológicas, queixas do paciente, orientação geral sobre o Hospital e observações do enfermeiro.

4.2.2 - Ficha de recomendações: onde são anotadas todas ocorrências com o paciente desde admissão até alta.

4.2.3 - Ficha de internação: preenchido pelo SAME e enviada à Unidade de Internação, juntamente com Ficha Clínica e RX anteriores, contendo informações sociais e médicas.

\section{3 - Objetivos Gerais:}

4.3.1 - Comunicação da equipe de profissionais.

O Serviço de Enfermagem do Instituto "Dante Pazzanese" de Cardiologia, mantém encontro de equipes para passagem dos plantões nas várias unidades do Serviço. Na Unidade de Internação a "passagem de plantão" é feita com equipe multiprofissional, (Assistente-social, 
MARIA, V.L.R. e colaboradores - Evoluçāo do paciente: anotaçōes de enfermagem no kardex e passagem de plantão com equipe multiprofissional. Rev. Bras. Enf.; DF, $30: 237-243,1977$.

Enfermeiros, Terapeuta Ocupacional, Auxiliares de Enfermagem, Atendentes, Professores e Alunos em estágio e ocasionalmente médico residente), a equipe se comunica diariamente nos periodos da manhā, tarde e noite.

Quinzenalmente em reuniāo previamente planejada são abordados problemas gerais do grupo e do paciente. No decurso do trabalho as comunicaçōes se desenvolvem facilmente devido à planta física, a unidade de internação e terapias ficam ao longo de um corredor medindo mais ou menos 100 metros que centraliza pacientes e serviços.

A comunicação é o instrumento mais completo de trabalho. O enfermeiro da equipe multiprofisisonal funciona como vínculo ou central de relacionamento.

E o coordenador do interrelacionamento dos componentes da equipe de saúde; a nossa preocupação é o paciente como pessoa - não como 1 (um) caso, número de leito ou 1 (um) diagnóstico.

O profissional de enfermagem para assumir liderança no trabalho de equipe não pode estar alheio ao processo de comunicação, ao tratamento que deve dispensar à mensagem recebida daqueles que contatuam com o paciente, não pode estar alheio a escolha do canal de comunicação (experiência, símbolos, etc.) e principalmente à percepção do feedrack e situações empáticas.

Segundo Laswell a fórmula da comunicação consiste em se estabelecer: Quem? Diz o que? Com que meios? Com que final? Quem? A fonte da comunicação, pode receber influências que determinam sucesso ou fracasso da mensagem. Depende das habilidades comunicativas, atitudes para consigo mesma, auto imagem positiva, etc. As anotaçōes do Kardex cristalizam "pontos de vistas, observação" que os elementos da equipe têm dos pacientes. Sendo a equipe mul- tiprofissional as fontes de comunicaçōes são várias também.

A quem? Receptor é o elemento mais importante na comunicação, quanto maior a habilfdade intelectual do receptor melhor será a comunicação. As experiências têm provado quanto maior a relação de status social maior é a aceitação da mensagem, mais eficiente a comunicação. Nossa equipe multiprofissional sendo composta na maioria de elementos de nível universitário têm trabalhado com mais compreensão.

Diz o que? A mensagem deve ser plarejada e expedida de modo a ter atenção do receptor pretendido. O enfermeiro como coordenador da equipe de trabalho seleciona e encaminha ao profijs sional próprio as mensagens recebidas do paciente envolvendo familia, etc., ou recebidos sobre o paciente. Os problemas "intimos" são registrados no Kardex mais não são passados no plantão.

Os meios (canal) usados pela equipe para detectar as mensagens (problemas) são: símbolos verbais escritos, falados, ouvindo o paciente, entrevistando-o, visitándo-o diariamente.

As reações do receptor como respostas aos problemas ouvidos, escritos e lidos do Kardex (Feed-back) nos ajudam a avaliar a eficiência do grupo e a validade da passagem do plantão. O conhecimento do problema estabelece uma interdependência entre paciente e equipe. A empatia é usada na comunicação. importantíssimo, usando a capacidade de nos colocarmos no lugar do outro e projetarmo-nos dentro de sua personalidade, sentir seus sentimentos, compreender suas expectativas, assim não estamos correndo o risco de tornarmo-nos indiferentes "frias" à problemática do paciente internado. Interferência em comunicação é toda circunstância pessoal ou ambiental que perturba o processo. No encontro da equipe durante a passagem de plantão 
MARIA, V.L.R. e colaboradores - Evolução do paciente: anotaçōes de enfermagem no kardex e passagem de plantão com equipe multiprofissional. Rev. Bras. Enf.; DF, $30: 237-243,1977$.

temos tido interferência ora de ordem pessoal a enfermeira que lê o Kardex tem voz monótona. Por outro lado a passagem de plantão sendo feita no correclor facilmente é interrompida por estranhos que querem informaçōes, serviçais que passam para trabalhar, etc.

4.3.2 - Orientação dos funcionários: através dos registros no Kardex o enfermeiro estabelece um plano imediato de ação, levando o funcionário a conscientizar-se do mesmo e adotar uma conduta terapêutica, correspondente.

4.3.3 - Fonte de informação sobre o paciente na ficha Kardex, vamos encontrar informaçōes sobre:

- estado físico, psíquico e social do paciente nas 24 horas.

- exames solicitados e realizados.

- encaminhamentos para outros setores e hospitais.

- mudanças de ordens e prescriçōes médicas.

- medicações especiais (heparina, revivan, cloreto de potássio, etc.).

- modificações e proibiçōes dietéticas.

- cuidados especiais, preparo para exames e para cirurgia, banhos no leito, mudança de decúbito, etc.

liares.

- solicitação e informação de fami-

- ocorrências de relacionamento (conflitos).

- paciente-enfermagem

- paciente-paciente

- paciente-familia

- paciente-equipe

- isolamento de paciente infectado.

- data provável de alta e execuçâo do plano de alta de enfermagem que consta de:

- orientação sobre dieta

- alimentos proibidos

- atividades (física-sexual)

- medicação a ser tomada: - em casa (dose e horário)
- em casos de emergência

- cirurgia realizada e evolução no trans e post operatório

- respostas do paciente: sintomas, manifestação e queixas.

4.3.4 - Catalizador das atividades realizadas com os pacientes.

através do Kardex que temos uma visão geral de todos os pacientes internados e consequentemente do seu estado de dependência de enfermagem (diagnóstico) pode-se então fazer o planejamento das atividades dos funcionários, revertendo numa melhor assistência com menor esforço.

As recomendaçōes são feitas pelo enfermeiro que orienta diretamente os funcionários sob suas ordens, facilitando a distribuição de serviços para sua equipe, que fica familiarizada com suas funções e sua relação com os outros membros.

Esta discriminação de tarefas é claramente definida e por escrito, evitando confusōes observadas em várias situaçōes, em que havia apenas interpretação oral das responsabilidades.

Baseada no Kardex, a discriminação ce tarefas é feita para cada membro da equipe pretendendo-se mostrar apenas a relação entre as tarefas e a diferenciação de funçōes.

No Instituto "Dante Pazzanese" de Cardiologia, utilizamos a escala diária de trabalho, com as especificaçōes.

Exemplo:

- Atendentes - preparos para cirurgia;

- banho no leito;

- encaminhamentos para banho de chuveiro;

- preparo de unidades;

- controle de peso;

- tricotomias;

- distribuição de alimentação. 
MARIA, V.L.R. e colaboradores - Evoluçāo do paciente: anotaçōes de enfermagem no kardex e passagem de plantāo com equipe multiprofissional. Rev. Bras. Enf.; DF, $30: 237-243,1977$.

- Auxiliares - administração de medicação;

- ajudar nos banhos;

- controle de sinais vitais;

- controle de diurese;

- curativos de cateterismo cardíaco.

- Enfermeiros - nas terapias presta cuidados integrais ao paciente $e$ desempenha atividades administrativas.

- na unidade de internação desempenha atividades administrativas e ocasionalmente presta cuidados de enfermagem diretamente ao paciente.

4.3.5 - Indicador de controle de Avaliação do Grupo:

A avaliação é um processo, contínuo. As anotações dos problemas do paciente, medidas tomadas para sua solução e ocorrências durante as 24 horas, proporcionam meios tangíveis de avaliação. $O$ paciente é sempre o indicador do sucesso da atuação da enfermagem com rẹlação aos cuidados prestados.

A Anotação é um elemento essencial para a estimativa. $\mathrm{t}$ um meio de comunicação entre os membros do Serviço de Enfermagem e o grupo de profissionais atins, constituindo o Kardex, uma fase riquíssima do plano total de cuidados.

Estes registros em si, já são um instrumento de controle automático das atividades desenvolvidas na unidade. Se houver falha de um plantão a anotação referente a determinado problema ou atividade não será feita, consequentemente, captada pelo plantão seguinte, que procurara sanar a falta e alertar a equipe, para evitar nova falha.

4.3.6 - Meio de pesquisa: para nós, é de alto valor. ressaltarmos, que as fichas Kardex, grampeadas e arquivadas, durante 5 anos, sem interrupção, nos ser- viram de base para pesquisa de trabalhos, incluso este, o que nos permitiu promover variaçōes e adaptações, transformando-o num elemento de grande valor dentro da equipe de saúde do Instituto "Dante Pazzanese" de Cardiologia.

\subsection{7 - Objetivo Especifico do Kardex}

Reunir todas as informaçōes sobre o paciente, encarando individualmente, orientando a equipe de saúde, para uma assistência integral ao paciente.

\section{5 - NORMAS DE UTILIZAÇAO:}

5.1 - As anotaçōes no Kardex, são de competência exclusiva do enfermeiro.

\section{2 - São utilizadas fichas individuais} para cada paciente.

5.3. - A linguagem para as anotaçōes deve ser objetiva, sem fugir da terminologia científica; que funciona como estimulador do conhecimento e promove o interesse do enfermeiro em acomparhar a evolução do paciente.

5.4 - Por ocrsiāo da admissão do paciente, é preenchida a ficha de entrevista e arquivada a ficha de internação, juntamente com o cartão de matrícula.

5.5 - Por ocasiāo da alta, é entregue o cartão de matrícula ao paciente e as fichas Kardex são grampeadas e arquivadas num armário, por não poder fazer parte do prontuário do paciente.

\section{6 - PROBLEMAS VIVIDOS PARA MANTE-LO}

6.1 - Não conscientização de algumas enfermeiras, que relutam em apresentar argumentos contra a utílização do Kardex, efetuando de maneira insatisfatória as anotaçōes de evolução do paciente.

6.2 - Nas terapias o Kardex foi introduzido, com o plano de enfermagem, mas passou a ser considerado uma "sobrecarga de serviço" já que a fícha nāo la para 
MARIA, V.L.R. e colaboradores - Evoluçāo do paciente: anotaçōes de enfermagem no kardex e passagem de plantão com equipe multiprofissional. Rev. Bras. Enf.; DF, 30 : 237-243, 1977.

o prontuário do paciente e havia a necessidade de repetir todas as anotações na folha de prescrição.

6.3 - Falta de pessoal, principalmente no Serviço Noturno, sendo que as observaçōes se reduziram ao essencial.

\section{7 - CRITICAS}

As anotaçōes dos auxiliares de enfermagem na folha de prescrição, e que portanto consta como documento no prontuário do paciente, são habituais e rotineiras, resumindo-se nos têrmos: sem queixas, Bem ou sem alteração; ao passo que no Kardex, são checados itens como: alimentação, eliminação, alteraçōes de sinais vitais e cuidados prestados. Estas informaçōes são obtidas pela visita do enfermeiro, somadas as observaçōes feitas pelos membros da equipe multiprofisisonal.

Como no Kardex a anotação é completa, o auxiliar se preocupa em comunicar à enfermeira fatos importantes ocorridos com o paciente e não os anotados na folha de prescrição e a ficha Kardex por não fazer parte no prontuário serve como fonte de pesquisa apenas para $o$ pessoal de enfermagem.

\section{8 - RECOMENDACOES:}

8.1 - Lutar pelo arquivamento das fichas, em anexo às fichas clínicas, pelo SAME. E de grande utilidade, ressaltar aqui, a microfilmagem.

8.2 - Abolir as anotaçōes de enfermagem dos Auxiliares, na folha de prescrição e habituar os médicos a procurar informaçōes dos pacientes no Kardex.

8.3 - Motivar continuamente as enfermeiras para efetuarem satisfatoriamente as anotaçōes, sem interrupçāo, motivação esta resultante do interesse de toda equipe em consultar o Kardex, e do fato, de saber, que seus registros, são documentos importantíssimos sob o ponto de vista legal e de pesquisa.

8.4 - Promover pesquisas, com objetivo de se encontrar sempre, maneira mais prática, mais eficiente e mais produtiva de registros.

8.5 - Realizar entrevistas periódicas com a equipe de saúde, com finalidade de avaliação da eficiência do Kardex, aceitando novas sugestōes de aperfeiçoamento e colocando-as em prática.

\section{9 - CONCLUSAO:}

Este sistema de registro, nos tem dado certa realização profissional, embora sa1bamos que o processo não esteja completo, já que para isto, precisaríamos estar registrando de uma maneira formal, com a execução do plano de enfer̃magem. Apesar das falhas, cremos que realmente, na prática, nos tem dado satisfação e motivação, acompanhadas de elogios também médicos, que podem confiar mais plenamente nos cuidados e nas informaçōes prestadas por este Serviço de Enfermagem.

Isto tudo nos levou a estudos e novas lutas para seu aprimoramento e mais uma vez repetimos: nosso trabalho de hoje, é resultante de nosso amor à nossa profissão, das falhas, dos estudos e principalmente do entusiasmo pelo que far.emos.

\section{0 - REFERENCIAS BIBLIOGRAFICAS}

1 - ABDALAH, F. G. Patient centered approaches to nursing. New York, The Macmilan Company, april, 1960.

2 - ANAIS do Congresso Brasileiro de Assistentes Sociais (I). Rio de Janeiro, 1974.

3 - BERLO, D. K. O processo da comunicaçāo. Río de Janeiro, Editora Fundo de Cultura, 1972.

4 - CarvaliHo, v. de. A problemática do diagnóstico de enfermagem. IN: Revista Brasileira de Enfermagem, 
MARIA, V.L.R. e colaboradores - Evolução do paciente: anotaçōes de enfermagem no kardex e passagem de plantão com equipe multiprofissional. Rev. Bras. Enf.; DF, $30: 237-243,1977$.

Rio de Janeiro, 1 e 2,: 114-125, janeiro/abril, 1972.

5 - COLIN, C. A comunicação humana. São Paulo, Editora Cultrix, 1971.

6 - GONÇALVES, L. H. T. Planejamento de cuidados de enfermagem a pacientes hospitalizados. Escola Paulista de Enfermagem. São Paulo.

$i$ - HORTA, W. A. O processo de enfermagem: fundamentaçăo e aplicação. IN: Revista de Infermagem em Novas Dimensóes, 8á Paulo. 1: 10-16, março/abril, 1975.

$\delta$ - HORTA, W. A. et al. O ensino dos instrumentos básicos de enfermagem. IN: Revista da Escola de Enfermagem U.S.P., São Paulo, 4: 5-20, 1970.

9 - KUREGANT, P. Plano de cuidados de enfermagem - necessidade administrativa. Escola de Enfermagem da U.S.P., Såo Paulo.
10 - LAMBBERTSEN, E. D. Equipe de enfermagem: organtzação e fuecionamento. Brasil, Associação Brasileira de Enfermagem, 1966.

11 - MARTINS, C. B. G. Avaliação da assistência de enfermagem. IN: Revista de Enfermagem em novas Dimensões, São Paulo, 1:113-118, julho/agosto, 1975.

12 - ORTIZ, M. de I. S. Plano de cuidado, uma experiéncia no Hospital das Clínicas. São Paulo.

13 - PEPLAU, H. Interpersonal relations in nursing. New York, G. F. Putnan's sons, 1952.

14 - REZENDE, A. L. M. O processo de comunicação como instrumental de enfermagem. IN: Revista de Enfermagem em novas Dimensōes Såo Paulo, 2: 98-111, maio/Junho, 1976. 